\title{
Unsur Tenaga Gerak dan Penerapannya pada Tari Seudati: Proses Kreatif di Sanggar Aneuk Metuah, Aceh Besar
}

jurnal tari, teater, dan wayang volume 4 number 2 ,

November 2021

page 88 - 94

\author{
Sabri Gusmail, Prasika Dewi Nugra ${ }^{1}$ \\ Program Studi Seni Tari, Jurusan Seni Pertunjukan, \\ Institut Seni Budaya Indonesia Aceh
}

\begin{abstract}
The Element of Motion and Its Application in Seudati Dance: The Creative Process at Aneuk Metuah Studio, Aceh Besar. This article is the research result which was conducted in Aceh Besar, which led to training activities to solve problems that occurred in the Aneuk Metuah Studio. The problem with the studio is about the dancers' body resistance when dancing the Seudati dance, namely that the dancers get tired quickly, which impacts the quality of the dance movement. The program is oriented towards increasing creativity in managing the energy element when dancing the Seudati traditional dance. This type of research is qualitative research using the action research method (action research). The researcher identified specific problems and determined actions as solutions to these problems. Furthermore, the research refers to the construction method of creating dance in Jacqueline Smith's book, translated by Ben Suharto, entitled Dance Composition: A Practical Guide for Teachers. The stages of activity include observation, determination of focus and preparation of training materials, transfer of materials, the performance of the Seudati dance, and evaluation of activities. The action is carried out in the form of training in the management of the energy element when dancing the Seudati dance. The material is delivered through audiovisual media and demonstrates it. Based on the process and the research results, it is found that the potential for the sustainability of the creative process can be carried out by the children of Aneuk Metuah studio in every training process in the future. It is hoped that this activity will have a long-term impact on the trainees in managing the elements of movement energy when dancing and increasing the artistic creativity in the studio.
\end{abstract}

Keywords: dance; training; elements of motion; Seudati

\section{Pendahuluan}

Koreografi (choreography) diartikan sebagai seni menata gerak untuk mengekspresikan ungkapan perasaan, maksud, dan pikiran seorang pencipta tari (koreografer) yang diekspresikan pada ruang dan waktu tertentu. Dengan demikian, dapat dipahami bahwa gerak merupakan substansi utama dalam terciptanya sebuah tari. Oleh sebab itu, diperlukan penguasaan teknikal dalam melakukan pergerakan tubuh dalam pertun- jukan sebuah tari walaupun setiap individu memiliki tingkatan dan cara yang berbedabeda dalam meningkatkan daya kreativitas. Dalam berkarya dan melakukan proses berkesenian, daya kreativitas perlu diasah dengan capaian respons kreatif, seperti melakukan proses eksplorasi dan improvisasi, serta melalui proses koreografi dengan berbagai permasalahannya yang memberikan satu kesempatan bagi koreografer ataupun penari untuk berpikir, merasakan, mengimajinasikan, serta mencipta (Hawkins, 1988: 43).

\footnotetext{
1 Alamat korespondensi: Program Studi Seni Tari, Jurusan Seni Pertunjukan, Institut Seni Budaya Indonesia Aceh. Jalan Teungku Tanoh Abee, Gampong Jantho Makmur Aceh Besar 23911. Email: sabrigusmail@ isbiaceh.ac.id; HP.: 08126491367.
} 
Salah satu pertunjukan tari di Aceh yang membutuhkan penguasaan teknikal yang baik adalah tari Seudati. Seudati berasal dari bahasa Arab syahadati atau syahadatain, yang berarti kesaksian bahwa tiada Tuhan selain Allah Swt. dan Nabi Muhammad Saw. adalah utusan-Nya. Pendapat lain mengatakan bahwa kata seudati berasal dari kata seurasi yang berarti harmonis atau kompak. Tari Seudati mulai dikembangkan sejak agama Islam masuk ke Aceh, dengan tujuan sebagai media dakwah untuk mengembangkan ajaran agama Islam.

Selain dimanfaatkan sebagai media dakwah, Seudati juga menjadi pertunjukan hiburan untuk rakyat. Menjadi tari yang menarik karena dalam pertunjukan dapat diceritakan berbagai hal melalui lantunan syair lagu yang biasanya disesuaikan dengan tempat dan hajatan pertunjukan. Banyak istilah dalam bahasa Arab yang digunakan dalam Seudati, antara lain istilah (pemimpin), syair (nyayian), dan saman (delapan).

Karakteristik tari ini terletak pada musik internal yang dihasilkan oleh tubuh penari. Penari dapat menghasilkan bunyi dari gerak tepukan tangan ke dada dan pinggul, hentakan kaki ke tanah, dan petikan jari. Gerakan tersebut menyatu dengan irama dan tempo lagu yang dinyanyikan. Gerak-gerak pada tari Seudati bervariasi, dinamis, lincah, dan merefleksikan semangat kekompakan. Tari Seudati sering ditampilkan pada aktivitas masyarakat dan dalam perhelatan festival yang diadakan oleh pemerintah daerah.

Pada perhelatan acara empat tahunan Pekan Kebudayaan Aceh (PKA) 2018 di Banda Aceh, terdapat kegiatan Seudati Tunang. Kegiatan seudati tunang merupakan pertandingan tari Seudati yang dilakukan oleh antar dua perwakilan daerah, dengan konsep penampilan saling bergantian hingga akan ditentukan pemenang oleh dewan juri. Biasanya, durasi pementasan dalam satu pertandingan dapat mencapai satu jam lebih. Banyak kasus kelelahan yang dialami oleh penari dan berdampak negatif terhadap penyajian tariannya. Hal tersebut dirasakan oleh tim Seudati perwakilan Kabupaten Aceh Besar. Mereka menyadari atas kelemahan penari dalam hal ketahanan tubuh. Pada kesempatan terpisah, terjadi perbincangan antara pimpinan sanggar Aneuk Meutuah (tim Seudati perwakilan Aceh Besar) dan peneliti terkait masalah yang dihadapi sanggar dan kemungkinan solusi yang dapat dilakukan untuk meningkatkan kondisi ketahanan tubuh penari ketika menarikan tari Seudati.

Di sisi lain, keterbatasan fisik pimpinan sanggar dalam mentransfer materi tari Seudati dan kurangnya waktu serta proses latihan, membuat tarian yang dipelajari jadi kurang maksimal, baik dalam latihan maupun pada saat penampilannya. Sebagai pelaku Seudati, Abdullah sangat menyadari atas permasalahan ketubuhan penari yang terjadi dalam pementasan tari Seudati. Oleh karena itu, praktik pengelolaan tenaga dalam menarikan Seudati diharapkan dapat menjadi penguat dalam pertunjukan-pertunjukan tari Seudati di masa mendatang. Di sisi lain, pola latihan yang tertata dapat meningkatkan animo kepedulian masyarakat dan generasi muda Gampong Suka Damai untuk belajar tari Seudati. Hal ini menjadi harapan besar dalam proses pewarisan tari Seudati yang dinilai mulai kurang diminati generasi muda. Pelestarian merupakan sebuah upaya berdasar pada kemampuan yang dimiliki oleh pelaku budaya ataupun kesenian, dan dasar ini juga adalah faktor-faktor yang mendukungnya, baik itu dari dalam maupun dari hal yang dilestarikan (Komala, dkk., 2020: 76).

Oleh karena itu, perlu dilakukan sebuah penyelesaian untuk menjawab permasalahan yang dihadapi mitra penelitian. Hal tersebut merujuk dari bagaimana menghasilkan koreografi yang baik. Tari yang baik harus didukung oleh kemampuan tubuh yang siap pakai, diperlukan waktu yang cukup, serta pencarian yang terus-menerus agar tubuh dapat berbuat lebih banyak di dalam koreografi (Sarjiwo, 2010: 85).

Guna mengaplikasikan keilmuan di bidang seni dan mambantu menyelesaikan 
masalah kepenarian dalam pementasan tari Seudati di Sanggar Metuah, maka dilakukan penelitian yang berorientasi pada pengelolaan tenaga sebagai salah satu unsur gerak tari. Sumandiyo Hadi (Nugra, 2018: 42) menekankan bahwa "gerak" adalah dasar ekspresi tari. Oleh sebab itu, "gerak" dipahami sebagai ekspresi dari semua pengalaman emosional. Pengalaman mental dan emosional diekspresikan lewat medium yang tidak rasional atau tidak didasarkan pada pikiran, tetapi pada perasaan, sikap, imaji, yakni gerak tubuh. Sementara itu, materi ekspresinya adalah gerakan-gerakan yang sudah dipolakan menjadi bentuk yang dapat dikomunikasikan secara langsung lewat perasaan. Kegiatan ini dianggap perlu dilakukan sebagai peran aktif perguruan tinggi seni dalam mengaplikasikan keilmuan yang dimiliki di tengah masyarakat. Pengelolaan tenaga menjadi penekanan dalam tindakan penelitian karena pada dasarnya dibutuhkan keahlian khusus bagi penari dalam mementaskan tari Seudati yang mengharuskan penari menghasilkan bunyi tubuh, menari sambil bernyanyi dan melakukan dinamika kecepatan pergerakan tubuh, serta durasi pertunjukan yang tidak tetap.

Jenis penelitian ini adalah penelitian kualitatif dengan menggunakan metode penelitian tindakan (action research). Penelitian tindakan merupakan pola atau metode dan kekuatan yang sering digunakan bagi para praktisi penelitian karena menuntut peneliti untuk terlibat dalam proses perbaikan atau perubahan perilaku. Metode ini dikembangkan yang memperbolehkan peneliti dan peserta bekerja sama untuk menganalisis sistem sosial dengan pandangan untuk mengubahnya (Moleong, 2014: 238).

Pendekatan pelatihan merujuk pada metode konstruksi mencipta tari dalam buku Jacqueline Smith, terjemahan Ben Suharto yang berjudul Komposisi Tari : Sebuah Petunjuk Praktis bagi Guru. Metode konstruksi I atau proses awal komposisi tari terdiri atas rangsang tari, tipe tari, perlakuan terhadap bahan untuk membuat gerak tari representasional dan simbolik, improvisasi, seleksi pemula gerak tari (Smith, 1976: 20). Oleh karena itu, kedudukan gerak sebagai substansi utama tari menjadi penting untuk dikelola dengan baik, salah satunya adalah unsur tenaga dalam gerak tari. Merujuk atas pentingnya unsur gerak sebagai substansi utama tari, pengelolaan unsur tenaga akan mempertegas karakteristik tari Seudati yang memiliki perpaduan gerak dan musik internal. Dengan demikian dapat mempertegas apa yang disampaikan oleh $\mathrm{F}$. $\mathrm{X}$. Widaryanto bahwa bidang tari ternyata dapat lebih leluasa memasuki, menembus, dan melampaui batas-batas yang selama ini tidak pernah terusik keberadaannya. Tubuh mengalami proses "transparansi" dalam kohesinya dengan bidang seni yang lainnya (Widaryanto, 2019: 57).

Tahapan yang dilakukan dalam kegiatan ini meliputi:

a. Observasi lapangan.

Langkah awal yang akan dilakukan dengan cara datang langsung ke sanggar Aneuk Metuah untuk mencari informasi yang berkaitan tentang sanggar tersebut. Narasumber yang terlibat adalah pimpinan sanggar Aneuk Metuah dan beberapa masyaraka setempat. Guna menjalin keakraban, tim pelaksana mengadakan sesi tanya jawab bersama masyarakat sekitar, anggota sanggar dan pimpinan untuk mengumpulkan informasi dan mencari data yang akurat. Di samping itu, tim juga mengamati kondisi keadaan sanggar serta melihat proses latihan Seudati di Balai Desa tempat mereka latihan.

b. Penentuan fokus dan persiapan materi pelatihan.

Setelah mendengar dan melihat di lapangan, ternyata anggota sanggar Aneuk Metuah memiliki potensi dan bakat yang belum tersalurkan pada latihan rutin sanggar. Oleh sebab itu, dapat ditarik permasalahan utama dan tindakan yang akan dilakukan dengan memfokuskan pada peningkatan kemampuan penari dalam pengelolaan unsur tenaga. Sehingga dalam menunjang kegiatan 
tersebut dipersiapkan materi-materi dalam pengelolaannya, yaitu berupa metode pemanasan yang baik, teknik pernafasan dan teknik kepenarian. Beberapa materi tersebut akan di demonstrasikan dalam pola gerak tari Seudati, sehingga secara tidak langsung terdapat 2 capaian yang diperoleh secara bersamaan, antara lain : penguasaan teknik tari dan materi gerak tari Seudati itu sendiri. Tim peneliti melibatkan mahasiswa sebagai peraga dalam mempersiapkan materi pelatihan dalam bentuk tertulis dan video tutorial singkat.

c. Transfer materi pelatihan di Sanggar Aneuk Metuah.

Pelatihan materi yang telah dipersiapkan akan dilakukan secara rutin dalam 3 kali/ minggu. Dimulai dari tahapan pemanasan yang baik, teknik tari dan teknik kepenarian dalam menari Seudati. Materi-materi tersebut akan bermuara pada bagaimana para penari dapat menari dengan baik pada saat menghadirkan musik internal, bernyayi dan melakukan gerakan-gerakan dalam tempo cepat. Setelah seluruh materi yang berkaitan dengan pengelolaan tenaga telah tersampaikan, maka akan dilakukan pengulangan materi di minggu-minggu berikutnya, serta mengaplikasikannya teknik-teknik tersebut dalam menari Seudati.

d. Pementasan tari Seudati.

Pementasan tari Seudati yang dimaksudkan pada kegiatan ini bertujuan untuk mengevaluasi sejauh mana kemanfaatan pelatihan yang dilakukan. Pementasan lebih menekankan pada aplikasi materi pelatihan dalam menari Seudati. Sehingga dari hasil pementasan dapat ditarik kesimpulan dan kekurangan dari pelatihan yang dilakukan. Pementasan tersebut dilakukan di Gampong Suka Damai dan dipertontonkan di tengah masyarakat pendukungnya. Lokasi pementasan bertujuan untuk meningkatkan animo berkesenian di desa tersebut dan penguatan ekosistem kebudayaan setempat.

e. Evaluasi kegiatan.

Evaluasi dilakukan disetiap minggu pe- laksanaan pelatihan, guna mendata kekurangan dan meningkatkan di pertemuan selanjutnya. Evaluasi akhir dilakukan dengan mementaskan tari Seudati. Tujuan pementasan untuk melihat capaian kemampuan penari-penari peserta pelatihan dalam menerapkan materi pengelolaan tenaga. Dokumentasi pertunjukan juga menjadi materi evaluasi keberhasilan pelatihan yang telah dilaksanakan. Mendata segala kendala dan kekurangan untuk peningkatan kinerja selanjutnya.

\section{Pembahasan}

Sanggar Aneuk Metuah berdiri secara permanen pada tahun 2016. Namun, pada tahun 1990-an sanggar ini telah melakukan aktivitas kesenian, terutama dalam pementasan tari Seudati. Terletak di Gampong Suka Damai, pemukiman Sare, Kecamatan Lembah Seulawah, Kabupaten Aceh Besar. Pada awalnya sanggar ini dibentuk karena pimpinan ingin melestariakan tari Seudati. Pimpinan sanggar merupakan salah satu penari sekaligus penyanyi (Aneuk Syahi) tari Seudati. Sanggar ini dibentuk di desa tempat beliau tinggal, dan sampai saat ini Sanggar Aneuk Metuah masih aktif dalam melestarikan tari Seudati. Jumlah angota sanggar terdiri dari dua puluh orang sebagai anggota tetap dan anak-anak Gampong Suka Damai yang ikut terlibat dalam latihan-latihan sanggar. Tempat proses latihan Sanggar Aneuk Metuah bertepatan di Balai Desa Gampong. Biasanya, mereka melakukan latihan rutin pada hari Senin, Rabu, dan Kamis.

Sanggar ini memiliki anggota dari anakanak hingga orang dewasa. Sebelum adanya sanggar tersebut, pimpinan yang bernama Abdullah sudah terlebih dahulu melakukan aktivitas berkesenian di beberapa kabupaten atau kota di Aceh hingga ke nasional untuk menampilkan tari Seudati. Dikarenakan faktor usia yang sudah semakin tua, beliau memilih untuk menetap di kampung halamannya dan mendirikan Sanggar Aneuk Metuah yang hanya fokus pada pelestarian tari Seudati. 
Kegiatan yang dilakukan peneliti berorientasi pada rancangan tahapan metode pelaksanaan kegiatan. Tim penelitian telah melakukan orientasi lapangan di lokasi kegiatan. Diperkirakan jarak tempuh dari tititk keberangkatan (kampus ISBI Aceh) menuju Sanggar Aneuk Metuah adalah tujuh puluh kilometer. Anggota sanggar didominasi anakanak yang masih duduk di bangku Sekolah Dasar (SD) dan Sekolah Menengah Pertama (SMP). Tim peneliti dan Ketua Sanggar Aneuk Metuah mendiskusikan jadwal pertemuan pelatihan agar kegiatan yang dilakukan tidak mengganggu waktu belajar wajib di sekolah masing-masing.

Materi yang dipersiapkan oleh tim pelaksana untuk kegiatan pelatihan di sanggar Aneuk Metuah terdiri dari materi gerak-gerak pemanasan dan unsur-unsur tenaga dalam tari (intensitas, aksen/tekanan dan kwalitas). Guna membantu dan mempermudah transfer

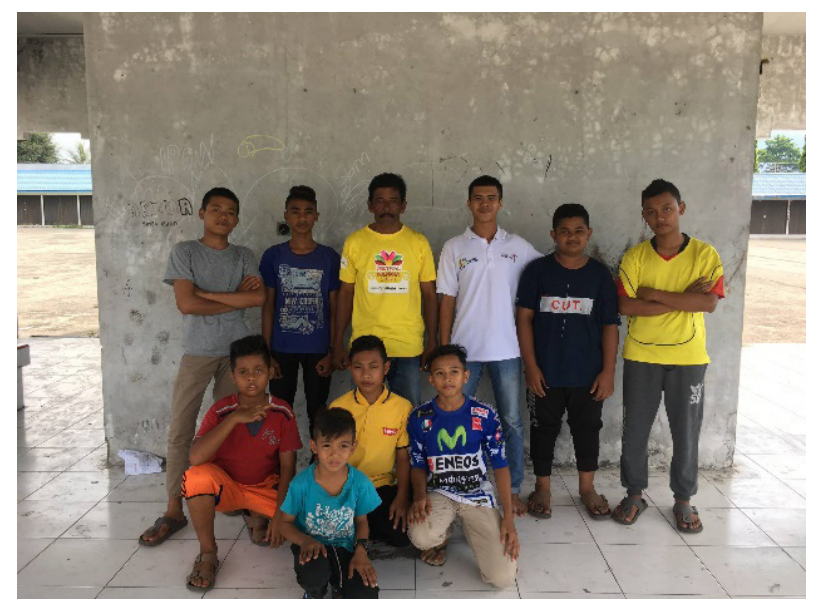

Gambar 1. Ketua dan beberapa anggota sanggar Metuah. (Sumber: Fadlan Aulia Nanda, 2019)

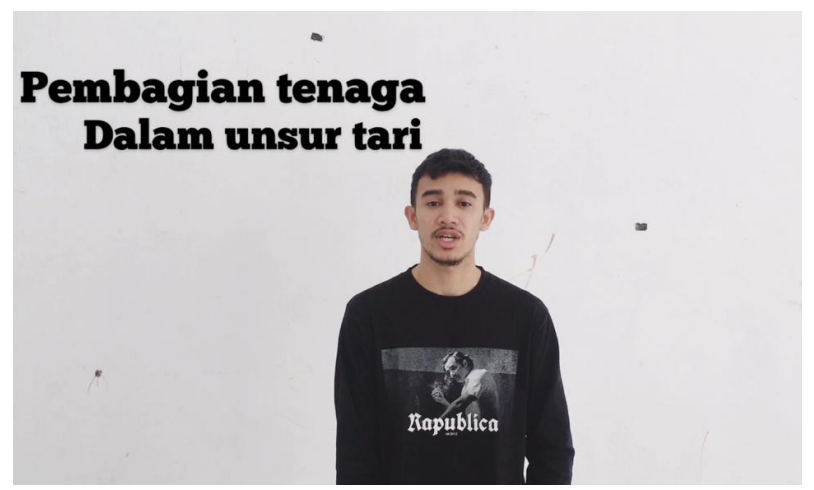

Gambar 2. Screenshot potongan materi pada video tutorial. (Sumber: Fadlan Aulia Nanda, 2019) materi di lapangan, tim mengemas materi tersebut dalam bentuk cetak dan video tutorial singkat. Video tutorial dapat diakses pada link: https://drive.google.com/file/d/ 1a93fxIS0-LUPMNDkefG_QBC4k2CxcGAz/ view? usp=sharing.

Transfer materi di lokasi dilakukan pada 2 kali pertemuan pada setiap minggu, dimulai pukul 16:00 WIB s.d. 18:00 WIB. Tim membagi materi dari gerak-gerak pemanasan hingga materi pokok secara berkala.

Unsur-unsur tenaga yang disampaikan dalam pelatihan antara lain:

1. Intensitas.

Berkaitan dengan tingkatan atau besaran tenaga yang digunakan, sehingga dapat menghasilkan tingkat ketegangan tertentu dalam sebuah tari.

\section{Aksen/tekanan.}

Penggunaan tenaga yang tidak rata. Gerakan

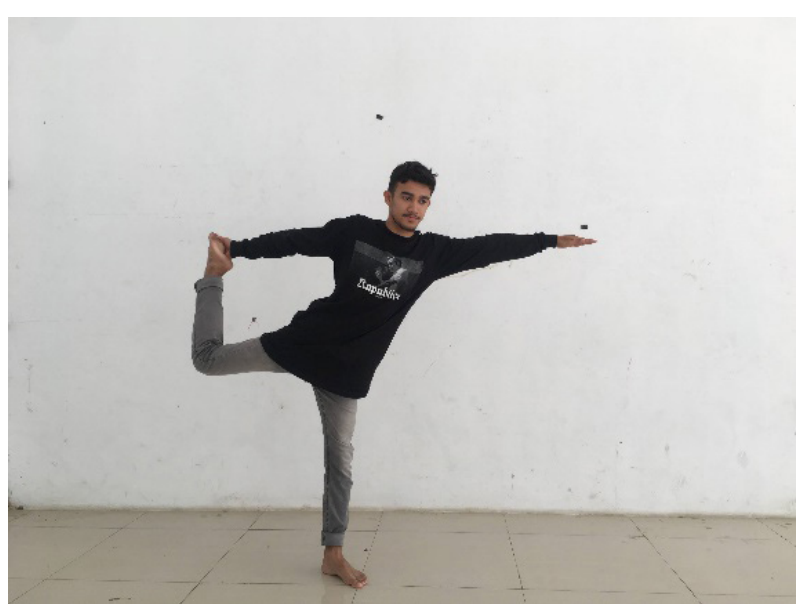

Gambar 3. Salah satu materi pemanasan guna meningkatkan ketahanan dan keseimbangan. Peraga: Suryadi. (Sumber: Yafto Pramana, 2019)

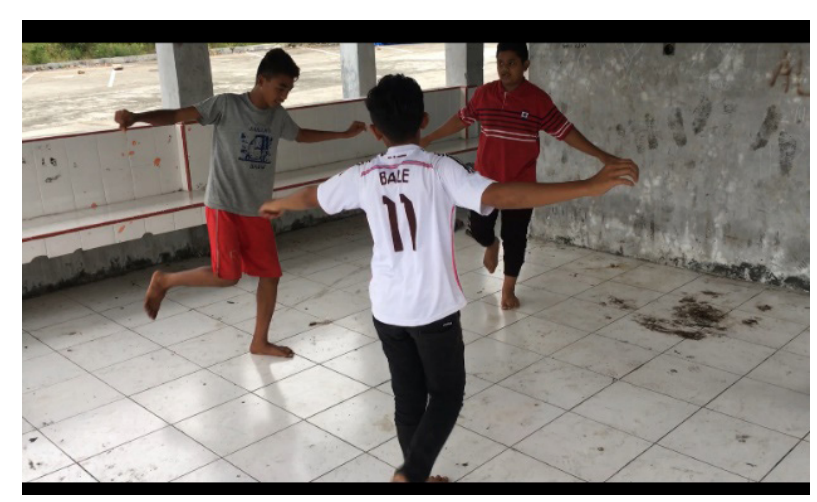

Gambar 4. Materi pengelolaan intensitas yang di praktikan pada gerak saleum syahi. (Sumber: Fadlan Auliananda, 2019) 
yang dilakukan secara tiba-tiba dan kontras. Aksen/tekanan biasanya dilakukan sebagai alat untuk mengenali dan membedakan pola-pola dan ritme-ritme gerak yang khas.

3. Kualitas.

Berkaitan dengan cara penggunaan dan penyaluran tenaga. Bagaimana mengawali gerakan, mengendalikannya dan mengakhiri gerakan.

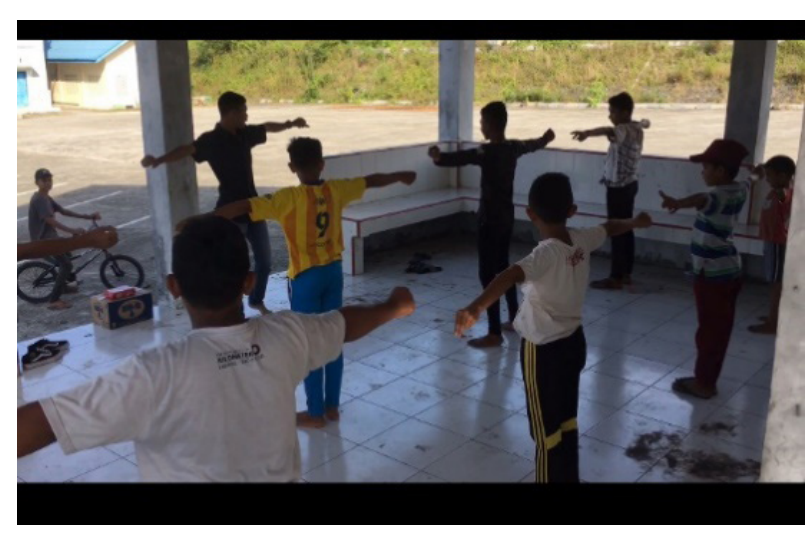

Gambar 5. Salah satu materi pengelolaan tekanan/ aksen yang dipraktikan pada gerak saleum syahi cepat. (Sumber: Fadlan Aulia Nanda, 2019)

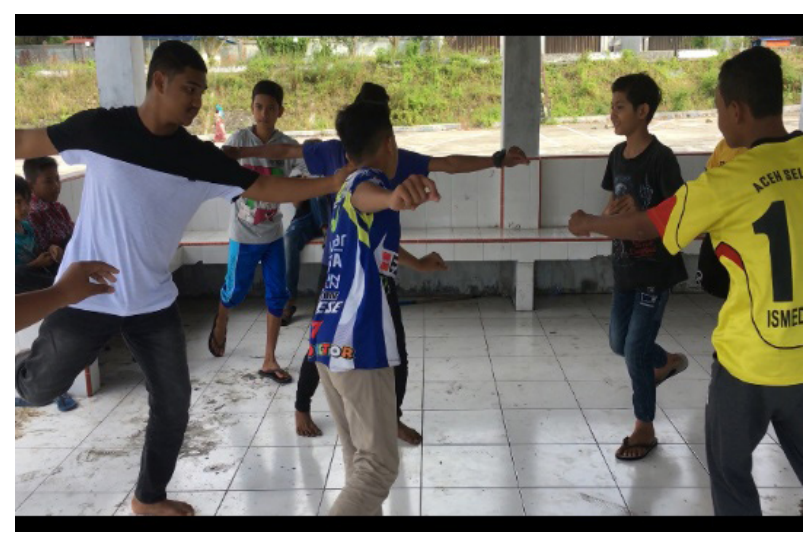

Gambar 6. Salah satu materi pengelolaan kualitas yang di praktikan pada gerak saleum syahi akhir.

(Sumber: Fadlan Aulia Nanda, 2019)

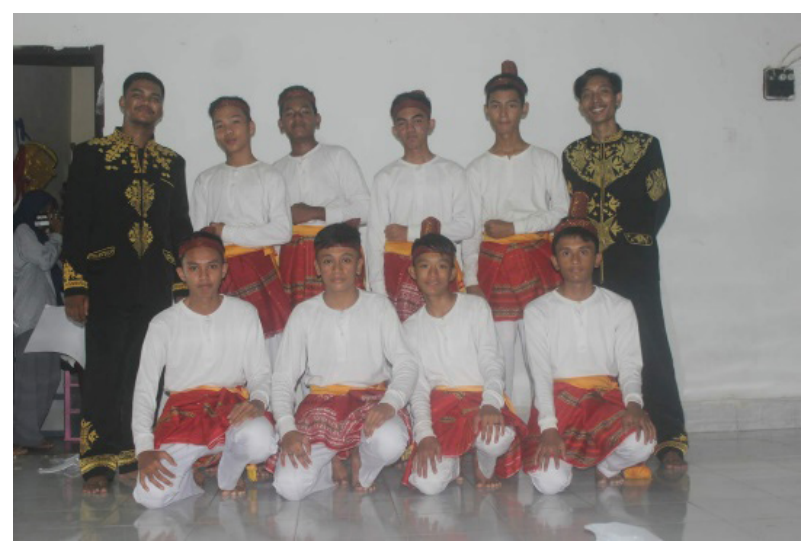

Gambar 7. Foto anak-anak sanggar Aneuk Metuah setelah pementasan. (Sumber: Arifin Harza, 2019)
Akhir pelatihan ditutup oleh uji coba pementasan tari Seudati yang ditarikan anakanak sanggar Aneuk Metuah sebagai peserta pelatihan. Kegiatan ini sebagai evaluasi hasil akhir keberhasilan pelaksanaan dan transfer materi yang telah dilakukan, tujuannya untuk melihat apakah kendala dan hal-hal lain yang perlu dipertimbangkan kembali untuk aktivitas selanjutnya, baik bagi peneliti maupun sanggar Aneuk Metuah.

Pelaksanaan kegiatan ini diharapkan dapat berdampak positif bagi pelaku seni tari di Sanggar Aneuk Metuah, khususnya pembinaan bagi penari anak-anak di sanggar tersebut. Secara umum pelatihan yang diberikan dapat meningkatkan kemampuan dan keahlian kepenarian serta berpeluang diterapkan sebagai materi rutin di sanggar tersebut. Luaran penelitian berupa materi pelatihan dalam bentuk video tutorial singkat dan video pementasan tari Seudati. Luaran tersebut diharapkan dapat membantu para penari dalam mengolah unsur tenaga pada saat menarikan tari Seudati. Sehingga pola latihanlatihan tersebut dapat diterapkan secara rutin di sanggar Aneuk Metuah dan menjadi percontohan bagi sanggar-sanggar lain di Aceh. Mampu meningkatkan pengalaman empirik peserta dari rangsang kinestetik yaitu pelaksanaan pelatihan dan rangsang visual dari menyaksikan materi pelatihan audio visual dapat menjadi bagian dalam proses kreatif menghasilkan pertunjukan tari yang baik.

\section{Penutup}

Penelitian ini dilakukan di Sanggar Aneuk Metuah, Kecamatan Lembah Seulawah, Kabupaten Aceh Besar. Melibatkan anak-anak sanggar yang sebagian besar masih duduk dibangku Sekolah Dasar (SD) dan Sekolah Menegah Pertama (SMP). Aktivitas pelatihan menjadi upaya dalam mengambil tindakan atas permasalahan yang terjadi di sanggar tersebut dan terfokus pada materi olah tubuh, teknik tari, dan penerapan pengelolaan tenaga 
pada saat menarikan tari Seudati. Tujuan yang diharapkan ialah agar kepenarian penaripenari sanggar dapat terbentuk, terutama dalam mengelola tenaga ketika menari Seudati.

Kegiatan yang telah dilakukan berpotensi meningkatkan kemahiran penari-penari Sanggar Aneuk Metuah dalam menari, terutama pada tari seudati. Pengelolaan tenaga tari dapat memperkaya pengetahuan dan teknik gerak baru bagi peserta guna menerapkannya pada saat latihan ataupun pementasan. Materi pelatihan yang diberikan dalam bentuk video tutorial dijadikan sebagai perbendaharaan dokumen bagi Sanggar Aneuk Metuah untuk panduan melakukan latihan secara berkesinambungan. Sementara itu, artikel ini diharapkan mampu menjadi perbendaharaan tulisan yang bersumber dari aktivitas penelitian kemitraan bersama komunitas masyarakat.

Kegiatanpenelitianmelibatkanmahasiswa dengan tujuan dapat menerapkan ilmu yang diperoleh pada saat pendidikan. Metode pelaksanaan kegiatan meliputi: observasi lapangan, penentuan fokus dan persiapan materi, transfer materi, serta pementasan tari Seudati. Materi pelatihan, antara lain: gerakgerak pemanasan, pengelolaan intensitas, tekanan atau aksen, dan kualitas. Pelatihan ini bertujuan untuk meningkatkan wawasan ilmu tari dan membantu penari-penari Sanggar Aneuk Metuah dalam mengelola tenaga pada saat menarikan tari Seudati.

Hasil kegiatan pelatihan secara khusus dapat bermanfaat bagi Sanggar Aneuk Metuah guna menjawab permasalahan yang terjadi di sanggar. Hal ini dilakukan sebagai solusi dalam memecahkan masalah yang dihadapi sanggar terkait dengan stamina dan ketahan tubuh penari saat menari. Di sisi lain, luaran kegiatan ini juga akan bermanfaat bagi dunia pendidikan, terutama bagi mahasiswamahasiswa jurusan seni pertunjukan dalam pengayaan pengetahuan. Kedepannya pelatihan ini diharapkan dapat menjadi solusi untuk meningkatkan keahlian dan menjadi materi rutin latihan secara berkesinambungan yang diterapkan di Sanggar Aneuk Metuah, Kecamatan Lembah Sulawah, Kabupaten Aceh Besar.

\section{Ucapan Terima Kasih}

Terima kasih penulis ucapkan kepada Institut Seni Budaya Indonesia (ISBI) Aceh sebagai perguruan tinggi tempat penulis bernaung. Apresiasi diberikan kepada Syech Abdullah sebagai Pimpinan Sanggar Aneuk Metuah, dan anggota sanggar yang sangat antusias dalam pelaksanaan kegiatan.

\section{Kepustakaan}

Gusmail, S. 2019. Peningkatan Kreativitas Pengelolaan Unsur-Unsur Gerak Tari di Aceh Besar. DESKOVI: Art and Design Journal, Vol. 2 (No 1), 53-58.

Hawkins, A. M. 1988. Creating Through Dance (Revised Edition). Disadur oleh Y. Sumandiyo Hadi. 2003. Mencipta Lewat Tari. Yogyakarta: Manthili.

Komala, S. T., Supriyanti, S., \& Martiara, R. 2020. Pelestarian Tari Andun pada Masyarakat Bengkulu Selatan. Dance and Theatre Review: Jurnal Tari, Teater, dan Wayang, Vol. 3(No 2), 72-81.

Moleong, L. J. 2014. Metodologi Penelitian Kualitatif Edisi Revisi. Bandung: PT. Remaja Rosdakarya.

Nugra, P. D. 2018. Fenomena Insomnia Sebagai Rangsang Penciptaan Karya Tari Tidak Tidur.Jurnal Puitika, Vol. 14 (No 1), 38-50. Sarjiwo. 2010. Teknik Pengelolaan Tenaga : Kajian Dalam Koreografi Garap Tunggal. Resital, Vol. 11(No 1), 81-91.

Smith, J. 1976. Dance Composition: A Pratical Guide for Teacher. Terjemahan Ben Suharto. 1985. Komposisi Tari, Sebuah Pertunjukan Praktis Bagi Guru. Yogyakarta: Ikalasti.

Widaryanto, F. X. 2019. Menyoal Ketubuhan dan Nilai Performatifnya. Dance and Theatre Review: Jurnal Tari, Teater, dan Wayang, Vol. 2(No 2), 53-63. 